\title{
Effect of Morphological Differences on the Cold Formability of an Isothermally Heat-Treated Advanced High-Strength Steel
}

\author{
IRMGARD WEIßENSTEINER $\odot,{ }^{1,3}$ CLEMENS SUPPAN,${ }^{2}$ \\ THOMAS HEBESBERGER, ${ }^{2}$ FLORIAN WINKELHOFER, ${ }^{2}$ \\ HELMUT CLEMENS, ${ }^{1}$ and VERENA MAIER-KIENER ${ }^{1}$
}

\author{
1.-Department of Physical Metallurgy and Materials Testing, Montanuniversität Leoben, \\ Leoben, Austria. 2.-voestalpine Stahl GmbH, Linz, Austria. 3.-e-mail: irmgard. \\ weissensteiner@unileoben.ac.at
}

\begin{abstract}
Steel sheets of Fe-0.2C-2Mn-0.2Si-0.03Ti-0.003B (m\%) for the automotive industry were isothermally heat-treated, comprising austenitizing and subsequent isothermal annealing at temperatures between $300^{\circ} \mathrm{C}$ and $500^{\circ} \mathrm{C}$. As a consequence, microstructures ranging from granular bainite over lower bainite to auto-tempered and untempered martensite were obtained. In tensile, hole expansion and bending tests, the performances in different forming conditions were compared and the changes of microstructure and texture were studied by complementary electron backscatter diffraction (EBSD) analyses. Samples with granular bainitic microstructures exhibited high total elongations but lower hole expansion ratios; in subsequent EBSD and texture analyses, evidence for inhomogeneous deformation was found. In contrast, the lath-like bainitic/martensitic microstructure showed higher strength and lower elongation to fracture. This results in a reduced bendability, but also in a high tolerance against damage induced by the shearing of edges, and, thus, allows homogeneous deformation to higher strains in the hole expansion test.
\end{abstract}

\section{INTRODUCTION}

Cold-forming operations of advanced highstrength steels (AHSS) play an important role in applying lightweight design to automotive vehicles. Increasing complexity and increasing loads during the forming operations, such as bending, deep drawing or stretch flanging, require knowledge of the material's deformation and damage mechanisms. ${ }^{1}$ Mechanical tests allow the classification of different materials or heat treatment conditions, but only the local characterization of the processes in the microstructure provides insight into the processes that are necessary to accommodate the macroscopic strains. Within this study, a variation of microstructural constituents is realized by applying different isothermal transformation temperatures. This allows for a comparison of the suitability of individual constituents for different forming operations.

The performance in bending tests (BT), indicating the roll forming and crash properties of a material, is superior in complex-phase steels compared to dual-phase steels. The low yield to ultimate tensile strength ratio provides a high potential for deformation. Besides the microstructure, the homogeneity and the anisotropy of the material, resulting from the rolling and annealing process, also has to be considered..$^{2-4}$ Especially in the outer surface, hardness differences in the individual phases, and the morphology as well as the initial texture, are critical for the bendability. ${ }^{5,6}$ Hole expansion tests (HET) allow the evaluation of the stability of punched edges. There, the pre-damage of the punching has a high influence on the expandability of the hole. Coarse grains and significant strength differences in the microstructural constituents have been reported to deteriorate the performance in the HET. ${ }^{7-9}$

During cold deformation a refinement of the dislocation structure of bcc metals is reported. The formation of dense dislocation walls followed by microbands and subsequent separation of cell blocks is primarily found in larger grains. ${ }^{10-12}$ The refinement of initially larger grains is also accompanied by the rotation of the lattice in favorable directions regarding the external loading direction. 
In cold-rolling experiments, different modes of deformation are experienced. At large thickness reductions leading to shear inside the sheets, texture components such as $\{112\}<111>_{\alpha}$, $\{110\}<211>_{\alpha}$ and $\{110\}<111>_{\alpha}$ have been observed. ${ }^{6,13-16}$ When plain strain in combination with a homogeneous deformation through the sheet was achieved, an increase of orientations positioned along the $\alpha$-fiber $(<110>$ I I rolling direction) has been reported. ${ }^{15,17-19}$ In this study, the description of the nature of the deformation of AHSS grades was approached by the texture development.

\section{EXPERIMENTAL PROCEDURE}

Low-alloyed steel sheet material of $1.5 \mathrm{~mm}$ thickness with a composition of Fe-0.2C-2Mn-0.2Si0.03Ti-0.003B (m\%) was-as shown in Supplementary Fig. 1-austenitized subsequent to cold rolling for $60 \mathrm{~s}$ at $850^{\circ} \mathrm{C}$ and quenched at $50^{\circ} \mathrm{C} / \mathrm{s}$ to an isothermal transformation temperature $\left(T_{\text {iso }}\right)$. The different sample conditions were produced by varying $T_{\text {iso }}$ from $500^{\circ} \mathrm{C}$ to $300^{\circ} \mathrm{C}$. After a holding time of $600 \mathrm{~s}$, the steel sheets were quenched to $20^{\circ} \mathrm{C}$, again using a cooling rate of $50^{\circ} \mathrm{C} / \mathrm{s}$.

After the heat treatment, the content of retained austenite was quantified by magnetization measurements according to Ref. 20 . There, the different saturation magnetization of a sample containing austenite compared to the saturation magnetization of an austenite-free sample allows the determination of the content of the retained austenite. The accuracy is stated in Ref. 20 to be better than $0.1 \%$. The sample size for this test was $15 \times 4 \times 1.5 \mathrm{~mm}^{3}$.

The annealed sheets were characterized mechanically by tensile tests (TT), three-point BT and HET at $20^{\circ} \mathrm{C}$. For TT according to ISO 6892-1, conducted on two samples in each orientation, the samples had an original width of $12.5 \mathrm{~mm}$, a parallel length of $36 \mathrm{~mm}$ and a gauge length of $25 \mathrm{~mm}$. Instrumented three-point BT were performed as described in Ref. 21 on two samples in each direction. The samples had a size of $30 \times 60 \times 1.5 \mathrm{~mm}^{3}$ and were tested in a setup with a roller distance of $3.5 \mathrm{~mm}$, a roller radius of $14.95 \mathrm{~mm}$ and a punch diameter of $0.4 \mathrm{~mm}$. Both bending angle and force were recorded for tests along the transverse (TD) and the rolling directions (RD). The bendability was quantified by the maximum bending force and the corresponding bending angle, which denotes the point before failure. HET were performed according to ISO 16630 standard, each of them on two samples in the individual heat-treatment conditions. During testing, the punch was moved at a speed of $1 \mathrm{~mm} / \mathrm{s}$ into the hole on the opposite site of the burr (which results from the holepunching process) until a crack appears through the full thickness of the sheet. The hole expansion ratio (HER) denotes the percental expansion of the punched hole.
The samples for metallographic examinations were prepared by a standard grinding and polishing procedure with low grinding pressure $(10 \mathrm{~N}$ over a sample diameter of $30 \mathrm{~mm}$ ). For electron backscatter diffraction (EBSD) analyses, the samples were etched with Nital and subsequently polished with an oxide polishing suspension (OP-U; Struers) for $17 \mathrm{~min}$.

The microstructural characterization of the material was conducted by scanning electron microscope on a FEI Versa 3D Dual Beam device in combination with EBSD on a Hikari XP camera and the software package OIM Data Collection 7 by EDAX.

The texture of the samples was analyzed from the EBSD data. For this purpose, fields of $116 \times 339 \mu \mathrm{m}^{2}$ with a step size of $300 \mathrm{~nm}$ were measured in the central area of the annealed sheets in the initial state. For a description of the initial microstructure, the EBSD scans had an area of at least $60 \times 60 \mu \mathrm{m}^{2}$ and a reduced step size of $80 \mathrm{~nm}$; therefore, pieces of all the heat-treatment conditions were imbedded together in one metallographic sample. EBSD scans with a minimum size of $85 \times 85 \mu \mathrm{m}^{2}$ were also taken on deformed samples for morphological and texture analyses. Orientation data for texture analyses were collected on all samples in the sheet center. Tensile test samples were analyzed at a distance of 50-150 $\mu \mathrm{m}$ from the fracture surface in the area of local necking (when present). The bending test samples were analyzed after testing the sample to failure-about $10^{\circ}$ from the bending axis or the crack, at a distance of $150 \mu \mathrm{m}$ to the outer surface. The HET samples were investigated at a distance of about $400 \mu \mathrm{m}$ from the hole edge in order to disregard effects of the prior punching of the hole.

The analysis of the data was performed by means of the EDAX software package OIM Analysis 8.0. For the quantification of the morphological features and for texture analysis, a grain confidence standardization cleanup was performed and data points with a confidence index below 0.1 were disregarded.

According to Refs. 22 and 23, the main tensile stress in HET samples is present in circumferential direction of the hole edge, therefore, the data were rotated in such a way that the main strain direction was aligned comparably to rolled sheets in order to analyze the change of the area fraction of the fibers. The EBSD data, derived from the BT samples, were also rotated according to the main strain applied due to the bending.

\section{RESULTS AND DISCUSSION}

\section{Initial Microstructure and Mechanical Properties}

Details of the microstructure in the center of the sheets after the isothermal heat treatment are shown in EBSD image quality (IQ) maps in Fig. 1a. The vertical direction corresponds to $\mathrm{RD}$ and the 

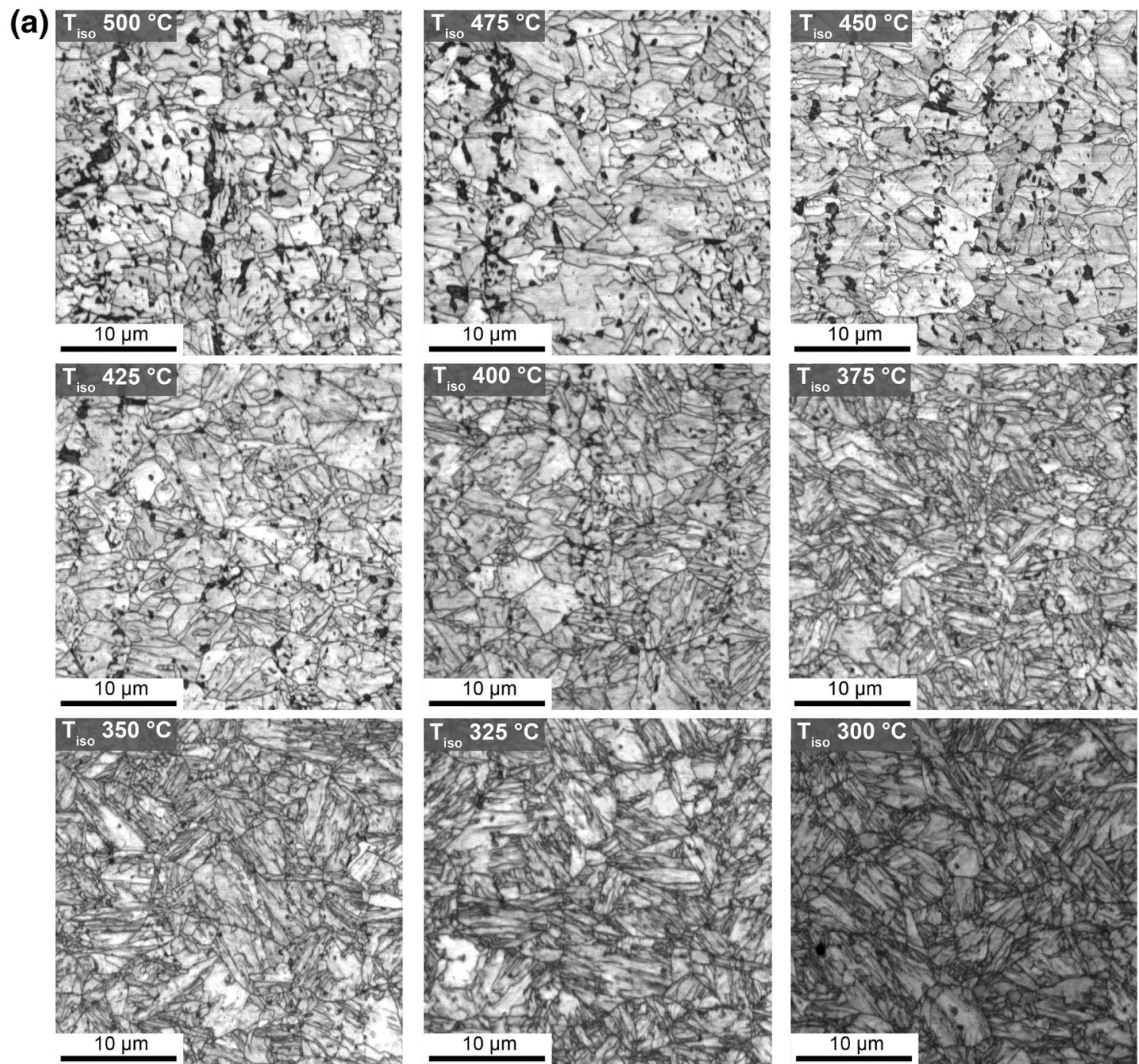

(b)
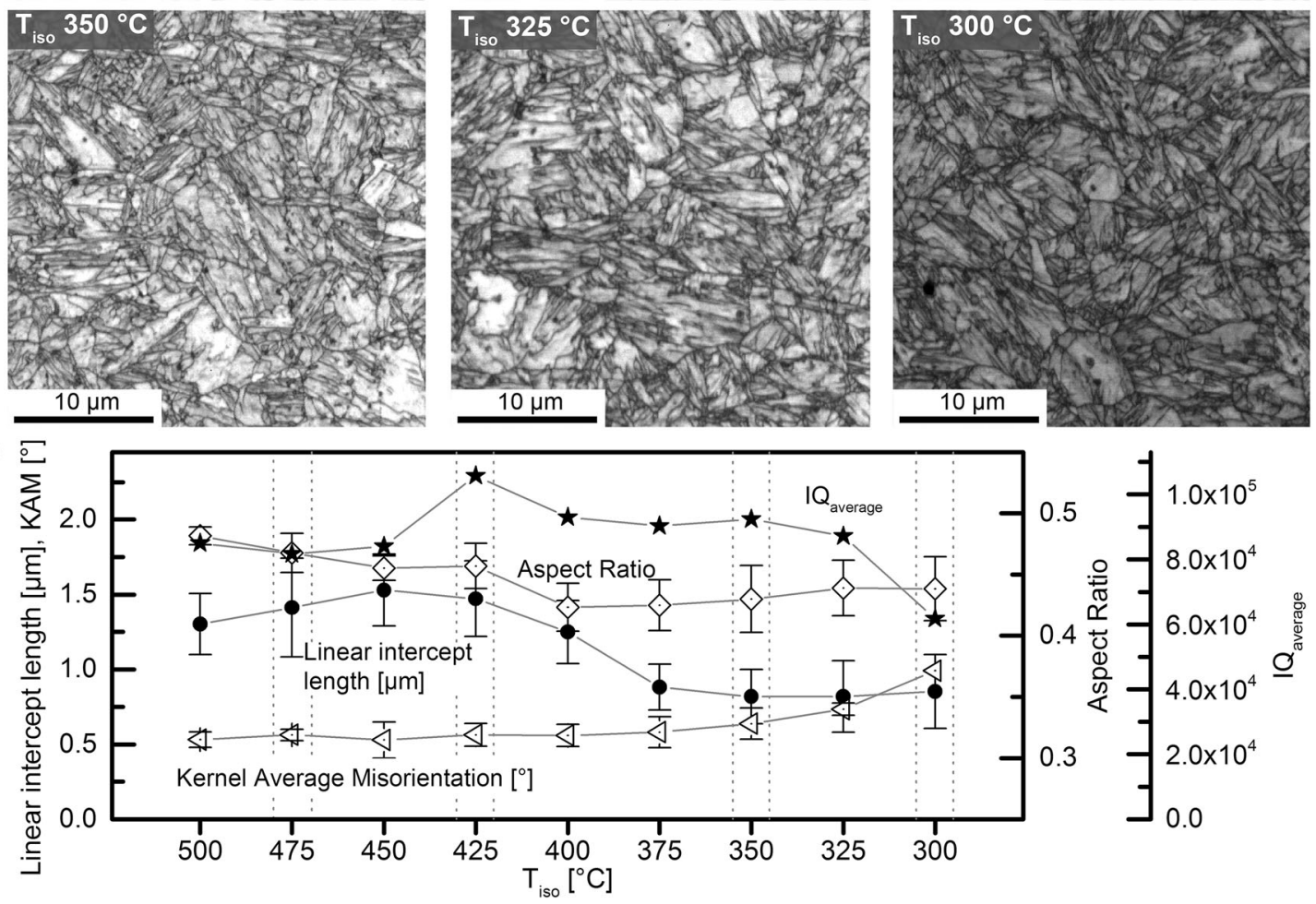

Fig. 1. (a) Image quality maps representing the center of the annealed Fe-0.2C-2Mn-0.2Si-0.03Ti-0.003B (m\%) sheets. The vertical direction corresponds to the rolling direction, the normal direction is positioned horizontally. The microstructures correspond to the resulting microstructures after an isothermal heat treatment in the range of $300-500^{\circ} \mathrm{C}$ (see labels). In (b), the quantified morphological description from EBSD data is depicted.

normal direction is positioned horizontally. The IQ is an indicator for the Kikuchi pattern brilliance. The darker the datapoints in the IQ maps, the poorer is their pattern quality. As also shown in Fig. 1, the IQ is reduced by grain boundaries, dislocations, and lattice strains. Therefore, it can be used for differentiation of the microstructural constituents. ${ }^{24-27}$ Due to the simultaneous and identical preparation of all the samples, any corresponding influences can be excluded. In a $T_{\text {iso }}$ range 
from $500^{\circ} \mathrm{C}$ to $450^{\circ} \mathrm{C}$, the ferritic components show a high IQ value and a globular morphology, which can be expressed through a high aspect ratio (defined by the length ratio of the minor to the major axes of the grain). Zajac et al. $^{28}$ describe similar microstructures as granular bainite. In all samples with $T_{\text {iso }}$ above $350^{\circ} \mathrm{C}$, the transformation of austenite to ferrite or bainite was not finished after $600 \mathrm{~s}$, so the final quenching step leads to the formation of the martensite-austenite (M-A) phase ${ }^{29,30}$ which appears as a dark globular constituent in the IQ maps. In the analyzed material, the $\mathrm{M}-\mathrm{A}$ islands were found mainly in the center of the sheets, and they are also the reason for a lower average $I^{27}$ and reduced linear intercept lengths in the conditions with an $T_{\text {iso }}>450^{\circ} \mathrm{C}$. The global IQ rises to a maximum at a $T_{\text {iso }}$ of $425^{\circ} \mathrm{C}$ and then decreases again. This is due to an increase of grain boundaries $^{27}$ connected with a change of the morphology below a $T_{\text {iso }}$ of $375^{\circ} \mathrm{C}$ to a lath-like structure without columnar aligned M-A islands. This is represented by a drop of the linear intercept lengths below $1 \mu \mathrm{m}$. At lower $T_{\text {iso, the }}$ IQ also decreases inside the grains, which can be linked to the diffusionless deformation in the bainitic/martensitic constituents. The reduction in aspect ratio at a $T_{\text {iso }}$ of $425^{\circ} \mathrm{C}$ also corresponds to the morphological change of the microstructure from granular to lath-like bainitic/martensitic. The martensite start temperature, calculated after, ${ }^{31}$ is between $366^{\circ} \mathrm{C}$ and $400^{\circ} \mathrm{C}$, which corresponds to the similar morphology of the microstructure in all the sample conditions produced at $T_{\text {iso }}$ of $375^{\circ} \mathrm{C}$ and below. At $T_{\text {iso }}>300^{\circ}$ $\mathrm{C}$, the martensite is auto-tempered during the isothermal heat treatment, and therefore shows higher IQ and lower kernel average misorientation (KAM) values, both indicating a lower amount of lattice strains in the sampled areas.

The change in microstructure leads to different performances in TT, BT and HET as shown in Fig. 2a-c. Besides high yield and tensile strengths of up to $850 \mathrm{MPa}$ and $1570 \mathrm{MPa}$, the lower bainitic

(b)
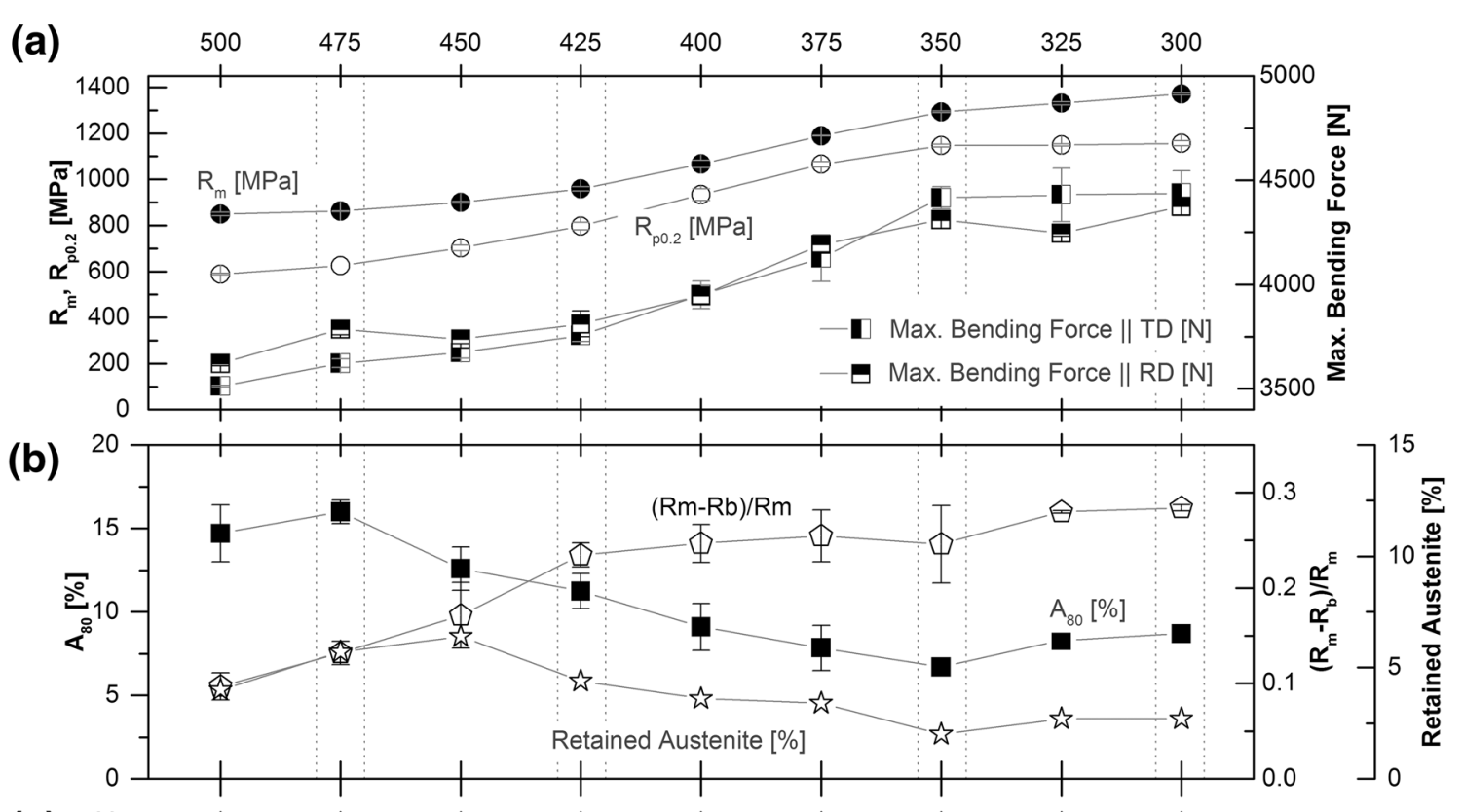

(c)

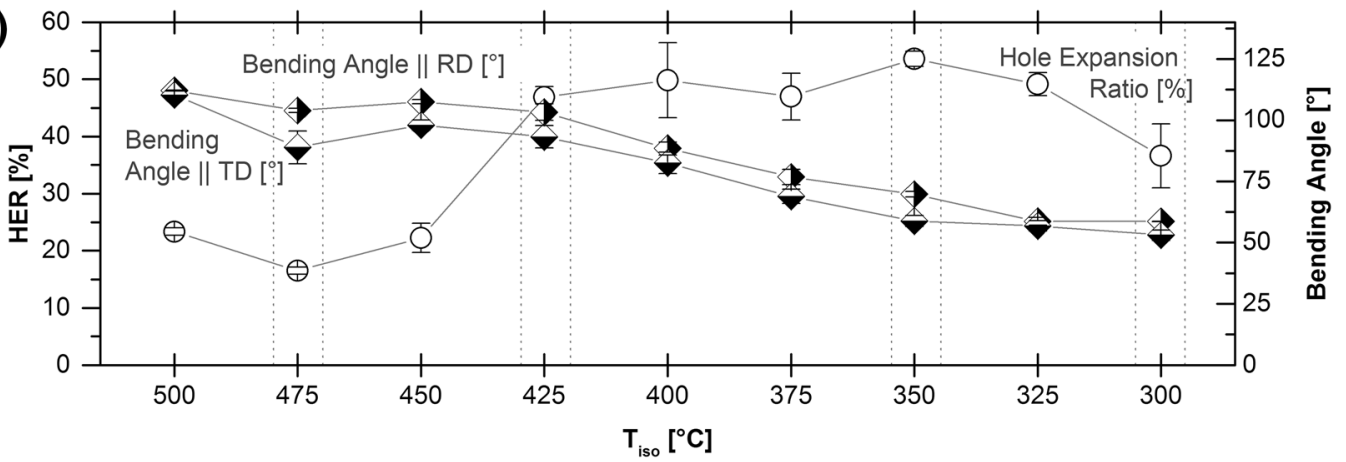

Fig. 2. Mechanical properties, derived from tensile tests (a,b), bending tests and hole expansion tests (c), as well as the amount of retained austenite obtained from magnetization measurements (b) for all isothermal heat treatments. 
and martensitic sheets show also the highest bending forces. In contrast, the total elongation to fracture $\left(\mathrm{A}_{80}\right)$ exhibits a maximum of $16 \%$ for the material isothermally annealed at $475^{\circ} \mathrm{C}$; nevertheless, it is reduced to $6.7 \%$ at a $T_{\text {iso }}$ of $350^{\circ} \mathrm{C}$. As a rough estimate of the capability of high local strains, the ratio of the difference between $R_{\mathrm{m}}$ and the breaking stress $R_{\mathrm{b}}$ to $R_{\mathrm{m}}$ was evaluated; it increases with decreasing $T_{\text {iso }}$.

High strain hardening is reported to reduce the HER due to the pre-damage which is promoted mainly in the ferrite-like microstructure components. Also, strain-induced martensitic transformation of the retained austenite to martensite, induced by the initial punching process, lowers the HER as well as the significant differences in the strength of the M-A constituent and the surrounding softer bainitic phases. ${ }^{7}$ Low $R_{\mathrm{m}}$ in combination with high values of $\mathrm{A}_{80}$, as present in the sample conditions with $T_{\text {iso }}$ above $400^{\circ} \mathrm{C}$, influence the bendability positively. As a consequence, the granular bainitic microstructure exhibits bending angles of up to $112^{\circ}$. However, columnar aligned heterogeneities associated with strong hardness differences, such as M-A islands beneath the sheet surface, act as crack initiators. ${ }^{3,6,32}$ In the investigated material, these are mainly present in the center of the sheets. The maximal strains concentrate to the outer regions of the sheets where the ductile (granular) bainitic phase accommodates the strain. The maximum bending angles for the samples tested in TD were constantly below the samples where the external strains were parallel to the RD.

Nonmetallic inclusions such as TiN can act as crack initiators in the investigated material, and matrix/particle decohesion was detected after the mechanical test. The ratio of intact/debonded interface around these particles was determined in the HET samples at a distance of $400 \mu \mathrm{m}$ from the hole edge. There, the fraction of the debonded interface was $19 \%$ and $23 \%$ in the samples $T_{\text {iso }} 425^{\circ} \mathrm{C}$ and $350^{\circ} \mathrm{C}$, respectively, whereas, in the sample

(a)

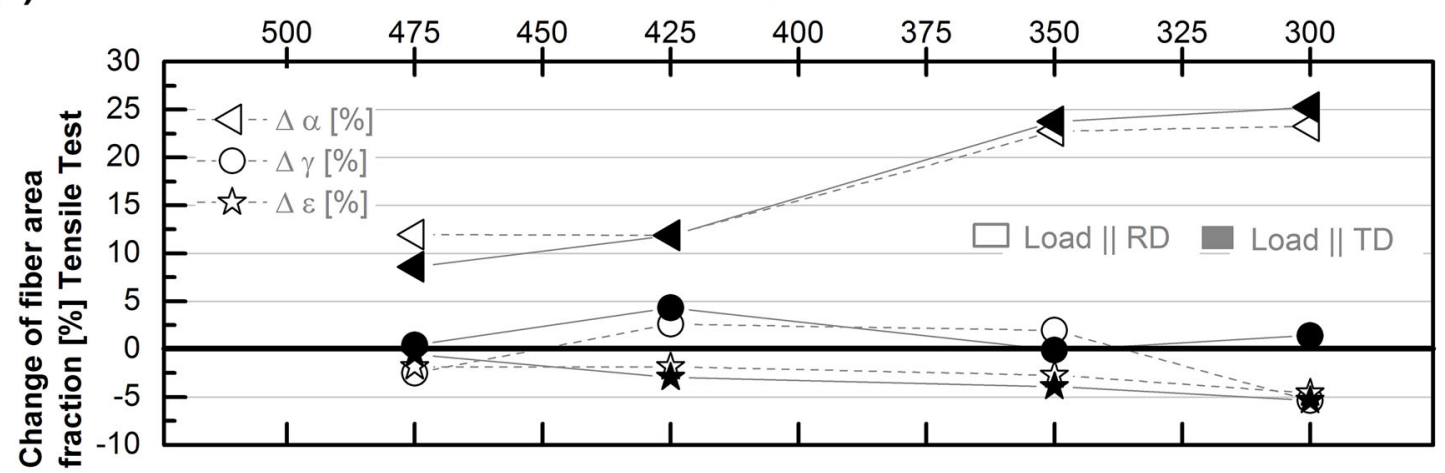

(b)
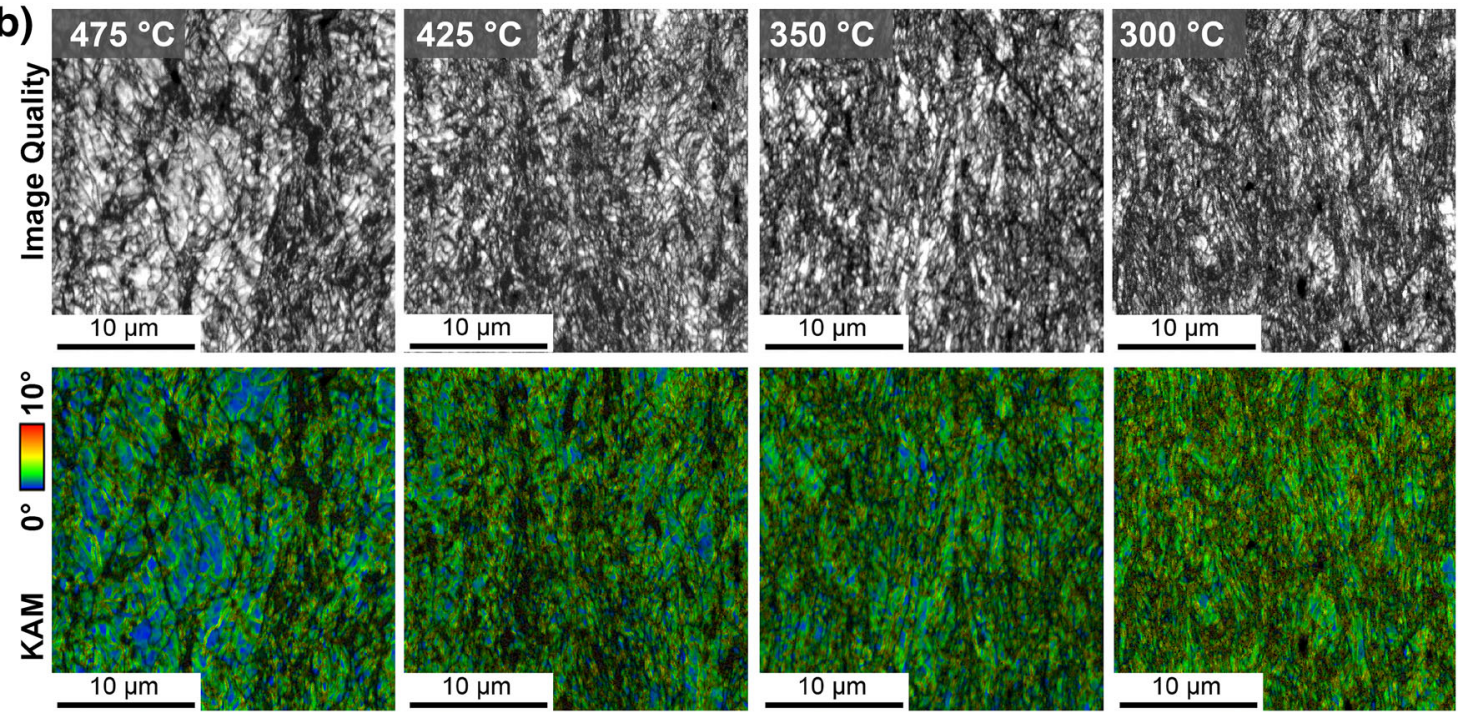

Fig. 3. (a) Change in area fraction of ideal fibers during tensile tests parallel to RD and TD. The micrographs in (b) show the cross-section in the center of the tensile sample $50 \mu \mathrm{m}$ from the fracture surface. The corresponding colored KAM maps of the $2 \mathrm{nd}$ neighbor at a step size of $80 \mathrm{~nm}$ and a maximum misorientation of $10^{\circ}$ show the local misorientations in the analyzed samples. 

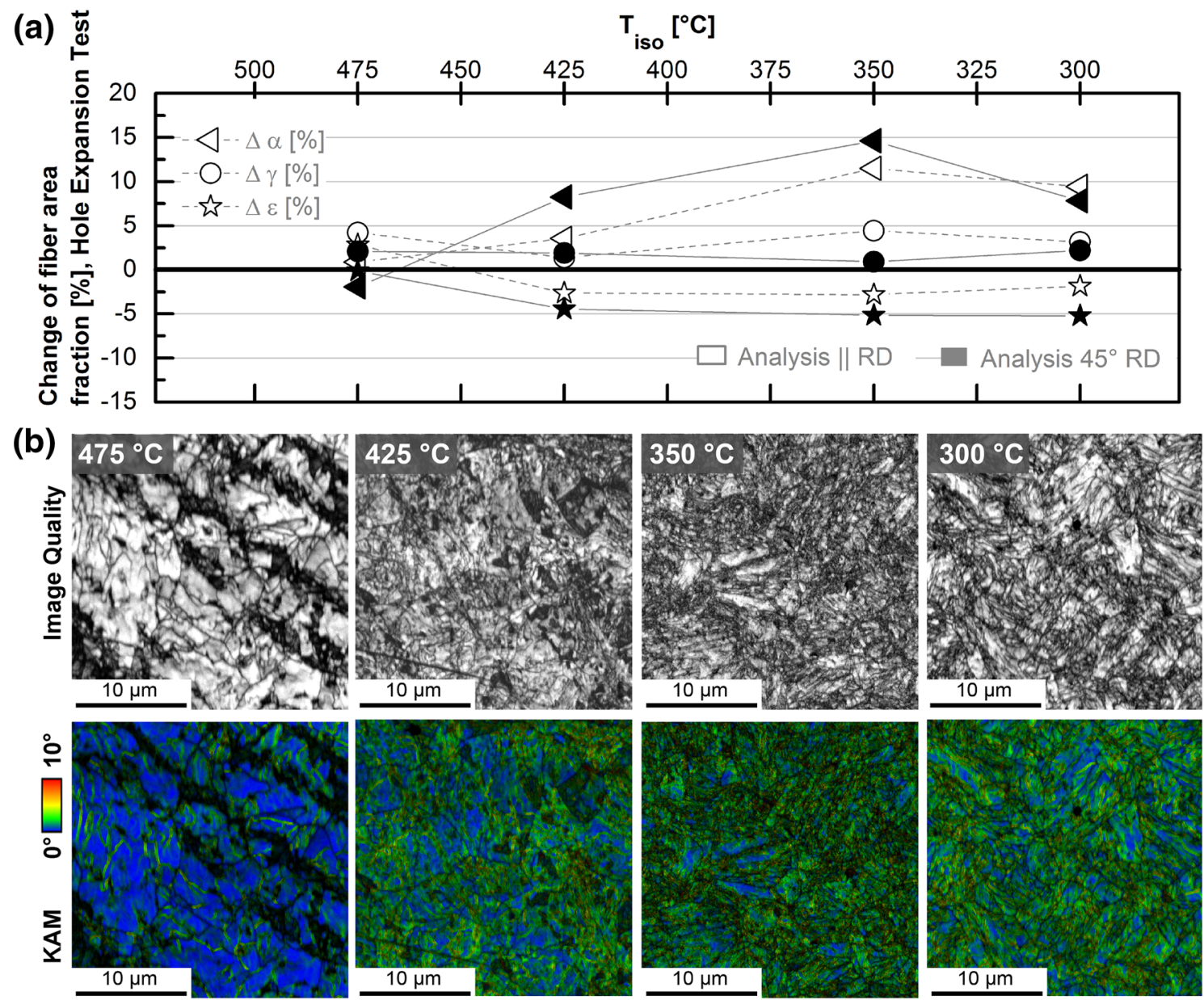

Fig. 4. (a) Change in area fraction of the ideal fibers after HET parallel to RD as well as at an angle of $45^{\circ}$. The analyses were performed at a distance of $400 \mu \mathrm{m}$ from the hole edge. In (b), the image quality maps and the corresponding colored KAM maps of the 2nd neighbor show the microstructure and distribution of the local misorientations in the analyzed sample areas.

conditions $T_{\text {iso }} 475^{\circ} \mathrm{C}$ and $300^{\circ} \mathrm{C}$, decohesion was observed along $78 \%$ and $63 \%$ of the interface, respectively.

\section{Effect of Deformation on Microstructure and Texture}

For more detailed microstructural analyses, four annealing conditions were selected because of a change in the morphology or the appearance of distinguished mechanical properties $\left(T_{\text {iso }} 475^{\circ} \mathrm{C}\right.$ : granular bainite with high area fraction of $\mathrm{M}-\mathrm{A}$ phase, lowest $\mathrm{HER} ; T_{\text {iso }} 425^{\circ} \mathrm{C}$ : transition range between granular and lath-like bainite; $350 \mathrm{C}$ : tempered martensite, highest HER; $300^{\circ} \mathrm{C}$ : least tempered martensite).

The development of preferred texture components was assessed by a comparison of the area fraction of ideal fibers in the center of the isothermally annealed sheets and the samples after mechanical testing. The material in the initial annealed state exhibits a certain area fraction of the ideal $\alpha$-fiber $(<110>|| R D), \gamma$-fiber $(<111>|| N D)$ and $\varepsilon$-fiber $(<110>$ I ITD $)$. These values were then compared with the rotated orientation data of the mechanically tested samples in the respective direction. After the mechanical tests, the grains with $<111>$ I I ND showed the highest density of geometrically necessary dislocations (evaluated in the OIM Analysis software according to Ref. 33) compared to the other fibers, which indicates a higher resistance against slip. ${ }^{34}$

The texture development after TT in RD as well as in TD is shown in Fig. 3a. As explained in the literature, the $\alpha$-fiber develops in homogeneously deformed bcc materials and is reported to strengthen continuously with increasing deformation. ${ }^{8,19,35}$ In the martensitic conditions $\left(T_{\text {iso }} 350^{\circ} \mathrm{C}\right.$ and $300^{\circ} \mathrm{C}$ ), the area fraction of the $\alpha$-fiber is increased by more than $21 \%$ in both testing directions. The total elongation is the lowest in the martensitic conditions, but reduction in thickness in the analyzed area is in turn higher in the bainitic/martensitic structures in the $T_{\text {iso }}$ range of $425^{\circ} \mathrm{C}, 350^{\circ} \mathrm{C}$ and $300^{\circ} \mathrm{C}$, exhibiting values of $48.0 \%$, $49.6 \%$ and $46.6 \%$, respectively. The granular bainitic material shows a local reduction in thickness of $33 \%$ in the analyzed area. Inhomogeneous 


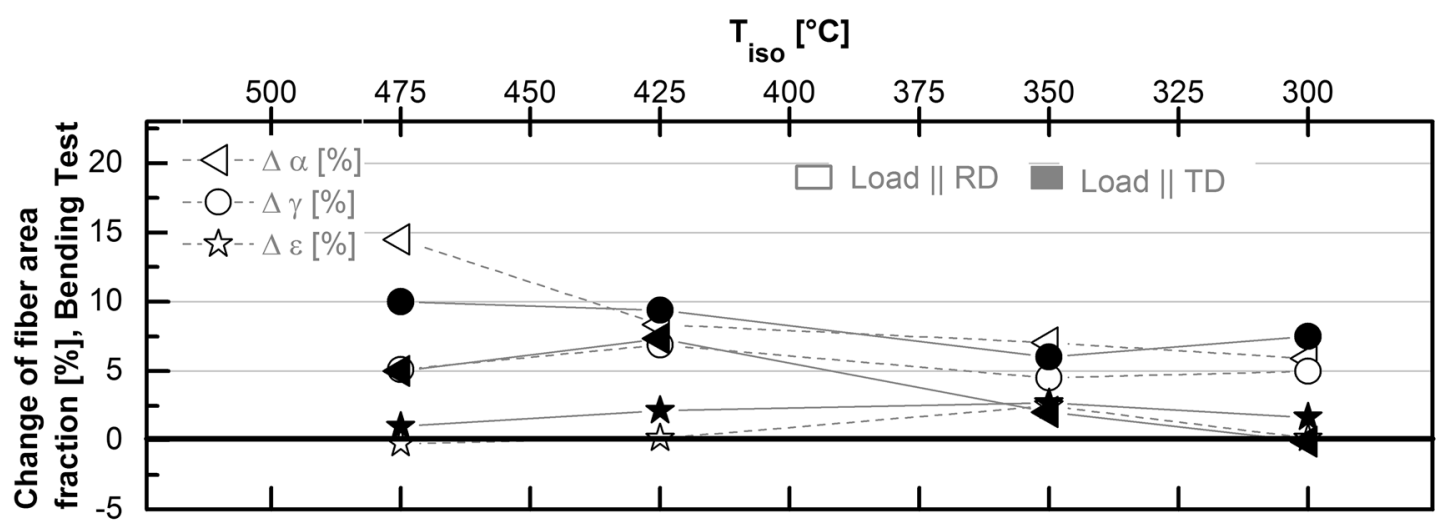

Fig. 5. Change in area fraction of the ideal bcc fibers after bending along RD and TD. The measurements were taken about $10^{\circ}$ from the bending axis or the central crack at a distance of $150 \mu \mathrm{m}$ to the outer surface.

deformation is reported to lead to a distinct development of an $\varepsilon$-fiber. ${ }^{16}$ After the TT, all tested conditions exhibit a slightly decreased area fraction of the $\varepsilon$-fiber in both testing directions.

In Fig. 3a, the texture development after the TT is expressed by the change of the area fraction of the fibers. The microstructure is shown in Fig. 3b by IQ maps and the corresponding KAM maps. In the granular bainitic structures, the plastic deformation is accomplished by localized deformation, especially along $\{110\}$ and $\{112\}$. The initial grains are almost completely divided into equiaxed cell blocks, separated by dense dislocation walls. ${ }^{10-12}$ In the sample conditions annealed at $350^{\circ} \mathrm{C}$ and $300^{\circ} \mathrm{C}$, the local strains in the analyzed areas are higher. These outcomes are in accordance with more distinct texture changes due to a "break-up" of the laths whereby the grains fulfil a lattice rotation individually.

Due to the deformation during the HET, the microstructural refinement (Fig. 4) again involves a certain rotation of the individual crystals in directions where the main gliding planes are aligned parallel to the main strain direction. This is the case for $<110>$ parallel to the circumferential direction, which corresponds to the points which are located along the $\alpha$-fiber in the orientation distribution function. Due to the homogeneous deformation trough all grains in the conditions with $T_{\text {iso }}$ of $425^{\circ} \mathrm{C}$ and below, the amount of $\varepsilon$-fibers decreases significantly.

The interfaces between matrix and nonmetallic inclusions of the material which shows the highest HER $\left(T_{\text {iso }} 350^{\circ} \mathrm{C}\right)$ exhibits the fewest defects, such as decohesion to the matrix or starting points of cracks, and the material condition also shows a low amount of M-A phase. These circumstances facilitate higher strains without failure. ${ }^{7,36}$ The local misorientation maps depict the homogeneity of the deformation in the different sample conditions. The condition of $T_{\text {iso }}$ of $475^{\circ} \mathrm{C}$ shows only a low density of small-angle grain boundaries in the initial coarse granular bainitic grains. Next to the M-A islands, the amount of lattice strains is slightly increased. Corresponding to the increased global deformation during HET, samples with high $\mathrm{HER}\left(T_{\text {iso }} 425^{\circ} \mathrm{C}\right.$ and $350^{\circ} \mathrm{C}$ ) exhibit increased KAM levels as indicated by the color code of the EBSD maps. For conditions of $T_{\text {iso }}$ of $350^{\circ} \mathrm{C}$ and below, the deformation of the microstructure takes place in and around the laths, and a refinement of the microstructure can also be observed. At the lowest $T_{\text {iso, }}$, individual laths remain with a lower dislocation density; however, the orientation of the laths is usually not correlatable to the global deformation direction. In Fig. 4, only the microstructures of the analyzed areas parallel to $\mathrm{RD}$ are depicted. The samples analyzed $45^{\circ}$ to $\mathrm{RD}$ have a similar appearance.

In BT, the highest tensile strains and the corresponding change in morphology and texture concentrate to the outer surface region. The conditions $T_{\text {iso }}=475^{\circ} \mathrm{C}$ and $425^{\circ} \mathrm{C}$ show comparable maximal bending angles before failure, whereby the difference in the maximal bending angle with regard to the loading direction is more pronounced in the first sample. Figure 5 shows that the deformation leads to a $66 \%$ weaker increase of the $\alpha$-fiber for the sample tested in TD, but in return to a 50\% higher gain in $\gamma$-area fraction. The samples isothermally annealed at $350^{\circ} \mathrm{C}$ and $300^{\circ} \mathrm{C}$ exhibit far lower bending angles, which also keep the change in the texture on a lower level. In all conditions, the amount of $\varepsilon$-fiber is about the same when compared to the initial condition.

Different performances in these three mechanical tests have so far been explained by varying microstructures. The view on the developed texture now additionally allows an estimate whether the global strains are distributed homogeneously through the microstructure or localized in easier deformable microstructural constituents. The first 
case correlates with an increase of the $\alpha$-fiber, whereas the $\varepsilon$-fiber involves shear components of bcc metals and occurs together with localized deformation in the softer constituents or along favored crystallographic planes.

\section{SUMMARY}

In this study, the effect of the morphological differences in isothermally heat-treated Fe-0.2C2Mn-0.2Si-0.03Ti-0.003B ( $\mathrm{m} \%$ ) sheets on cold deformation was investigated and the following conclusions can be drawn:

- Isothermal heat treatments at temperatures between $500^{\circ} \mathrm{C}$ and $425^{\circ} \mathrm{C}$ lead to a microstructure consisting of granular bainite with columnar aligned M-A islands. A reduction of $T_{\text {iso }}$ down to $375^{\circ} \mathrm{C}$ leads to a predominant constituent of bainite. Below $375^{\circ} \mathrm{C}$, the microstructure is martensitic and the morphology does not change any more; only the IQ shows a sharp drop at $300^{\circ} \mathrm{C}$. This can be explained by auto-tempering processes that take place at temperatures $>300^{\circ} \mathrm{C}$ during the isothermal heat treatment.

- Steels with ferritic or granular bainitic constituents exhibit lower yield to ultimate tensile strength ratios of $<0.17$ and high ductility in tensile and bending operations. The maximum bending angles before failure were greater than $100^{\circ} \mid \mathrm{IRD}$ and $>85^{\circ}$ । I TD. Homogeneous deformation, shown by the absence of shear components and IQ and KAM maps of the deformed lower bainitic and martensitic microstructures result in a positive performance in the tensile and hole expansion test. Damage initiation due to decohesion of heterogeneities such as nonmetallic inclusions first emerges at larger strains in these conditions.

- The mode of deformation could be correlated to local texture changes. Shear components in lowalloyed steels can mainly be found along the $\varepsilon$ fiber. In this work, crystals oriented along the $\varepsilon-$ fiber can be observed in more inhomogeneous deformation areas between different microstructural constituents or within larger initial granular bainitic grains as found in the samples with $T_{\text {iso }}>400^{\circ} \mathrm{C}$.

- Strong increase of the $\alpha$-fiber and the $\gamma$-fiber (up to $25 \%$ and $5 \%$, respectively), especially $\{111\}<110>$ and $\{111\}<112>$, can be correlated with homogeneous deformation over all orientations and microstructural constituents. Both are known as cold rolling texture components of bcc metals and distinct area fractions were detected in the samples which performed well in the mechanical tests.

\section{ACKNOWLEDGEMENTS}

Open access funding provided by Montanuniversität Leoben.

\section{OPEN ACCESS}

This article is distributed under the terms of the Creative Commons Attribution 4.0 International License (http://creativecommons.org/licenses/by/4.0/), which permits unrestricted use, distribution, and reproduction in any medium, provided you give appropriate credit to the original author(s) and the source, provide a link to the Creative Commons license, and indicate if changes were made.

\section{ELECTRONIC SUPPLEMENTARY MATERIAL}

The online version of this article (https://doi.org/ 10.1007/s11837-018-2833-0) contains supplementary material, which is available to authorized users.

\section{REFERENCES}

1. D.K. Matlock, and J.G. Speer, Mater. Manuf. Process. 25, 7 (2010).

2. K. Sugimoto, B. Yu, Y. Mukai, and S. Ikeda, ISIJ Int. 45, 1194 (2005).

3. D. Rèche, T. Sturel, A.F. Gourgues-Lorenzon, and J. Besson, Proc. Eur. Conf. Fract. 18, 1 (2010).

4. M. Kaupper and M. Merklein, CIRP Ann. Manuf. Technol. 62,247 (2013).

5. H. Tervo, A.J. Kaijalainen, T. Pikkarainen, S. Mehtonen, and D. Porter, Mater. Sci. Eng. A 697, 184 (2017).

6. A.J. Kaijalainen, P.P. Suikkanen, L.P. Karjalainen, and D.A. Porter, Mater. Sci. Eng. A 654, 151 (2016).

7. A. Karelova, C. Krempaszky, E. Werner, P. Tsipouridis, T. Hebesberger, and A. Pichler, Steel Res. Int. 80, 71 (2009).

8. K. Sakata, S. Matsuoka, and K. Seto, Highly Formable Sheet Steels for Automobile through Advanced Microstructure Control Technology (2003), pp. 3-8.

9. K. Hasegawa, K. Kawamura, T. Urabe, and Y. Hosoya, ISIJ Int. 44, 603 (2004).

10. N. Hansen, Mater. Sci. Technol. 6, 1039 (1990).

11. B. Bay, N. Hansen, and D. Kuhlmann-Wilsdorf, Mater. Sci. Eng. A 113, 385 (1989).

12. B. Bay, N. Hansen, D.A. Hughes, and D. Kuhlmann-Wilsdorf, Acta Metall. Mater. 40, 205 (1992).

13. A.C.C. Reis and L. Kestens, Solid State Phenom. 105, 233 (2005).

14. S.H. Han, S.H. Choi, J.K. Choi, H.G. Seong, and I.B. Kim, Mater. Sci. Eng. A 527, 1686 (2010).

15. J.H. Shin, M.S. Kim, S.I. Kim, S.J. Seo, and S.H. Choi, Mater. Charact. 118, 535 (2016).

16. H. Inagaki and T. Suda, Texture 1, 129 (1972).

17. D. Raabe, Mater. Sci. Eng. A 197, 31 (1995).

18. M. Hölscher, D. Raabe, and K. Lücke, Acta Metall. Mater. 42,879 (1994).

19. L.S. Tóth, J.J. Jonas, D. Daniel, and R.K. Ray, Metall. Trans. A 21, 2985 (1990).

20. E. Wirthl, A. Pichler, R. Angerer, P. Stiaszny, K. Hauzenberger, and Y.F. Titovets, International Conference on TRIP-Aided High Strength Ferrous Alloys (2002), pp. 6164.

21. P. Larour, B. Hackl, F. Leomann, and K. Benedyk, Proceedings of the IDDRG (2012), pp. 203-215.

22. S.K. Paul, M. Mukherjee, S. Kundu, and S. Chandra, Comput. Mater. Sci. 89, 189 (2014).

23. K. Wang, M. Luo, and T. Wierzbicki, Int. J. Fract. 187, 245 (2014).

24. S. Zaefferer, P. Romano, and F. Friedel, J. Microsc. 230, 499 (2008). 
25. S. Zaefferer, J. Ohlert, and W. Bleck, Acta Mater. 52, 2765 (2004)

26. S.L. Shrestha, A.J. Breen, P. Trimby, G. Proust, S.P. Ringer, and J.M. Cairney, Ultramicroscopy 137, 40 (2014).

27. J. Wu, P.J. Wray, C.I. Garcia, M. Hua, and A.J. DeArdo, ISIJ Int. 45, 254 (2005).

28. S. Zajac, V. Schwinn, and K.H. Tacke, Mater. Sci. Forum 500-501, 387 (2005).

29. A. Lambert, A. Lambert, J. Drillet, A.F. Gourgues, T. Sturel, and A. Pineau, Sci. Technol. Weld. Join. 5, 168 (2000).

30. E. Bonnevie, G. Ferrière, A. Ikhlef, D. Kaplan, and J.M. Orain, Mater. Sci. Eng. A 385, 352 (2004).
31. A.A. Gorni, Steel Forming and Heat Treating Handbook (Brazil: São Vicente, 2017).

32. D. Rèche, T. Sturel, O. Bouaziz, A. Col, and A.F. GourguesLorenzon, Mater. Sci. Eng. A 528, 5241 (2011).

33. S.I. Wright, M.M. Nowell, and D.P. Field, Microsc. Microanal. 17, 316 (2011)

34. T. Nguyen-Minh, J.J. Sidor, R.H. Petrov, and L.A.I. Kestens, I.O.P. Conf, Ser. Mater. Sci. Eng. 82, 12023 (2015).

35. M. Hölscher, D. Raabe, and K. Lücke, Steel Res. 14, 567 (1991).

36. C. Krempaszky, P. Larour, J. Freudenthaler, and E. Werner, Proceedings of the IDDRG (2014), pp. 204-209. 